\title{
Outcomes after mandibular third molar coronectomy
}

\author{
Desfechos após coronectomia de terceiros \\ molares inferiores
}

\author{
Lucas Borin MOURA ${ }^{1}$ iD 0000-0001-9009-6285 \\ Bibiana Dalsasso VELASQUES² ID 0000-0003-3990-6320 \\ Bhárbara Marinho BARCELLOS ${ }^{2}$ (DD 0000-0002-8454-8369 \\ Melissa Feres DAMIAN² iD 0000-0001-9037-7132 \\ Cristina Braga XAVIER ${ }^{2}$ ID 0000-0002-5290-2773
}

\section{ABSTRACT}

Coronectomy is an alternative technique to mandibular third molar removal to avoid inferior alveolar nerve impairment. It is indicated in cases where the dental roots are in close relationship with the nerve which results in a higher risk of damage and paresthesia. The coronectomy technique is considered a safe method to prevent inferior alveolar nerve injury, however it shows particular postoperative outcomes as migration and exposure of the retained roots, and possibility of additional intervention. The aim of this case series is to describe four different outcomes from coronectomy, in patients treated by the same protocol. The outcomes ranged from asymptomatic to migration, infection and root removal. Although the variety of outcomes, none of the patients showed inferior alveolar nerve impairment. Therefore, the main objective of coronectomy was reached.

Indexing terms: Mandibular nerve. Oral surgery. Third molar.

\section{RESUMO}

A coronectomia é uma técnica alternativa à extração de terceiros molares inferiores para a prevenção de lesão ao nervo alveolar inferior. É indicada em casos em que as raízes dentárias estão em íntimo contato com o nervo alveolar, resultando em um maior risco de lesão, e consequentemente parestesia. A técnica de coronectomia é considerada um método seguro para prevenção de lesões ao nervo alveolar inferior, entretanto pode apresentar desfechos pós-operatórios singulares, incluindo a migração e exposição dos remanescentes radiculares, além da possibilidade de intervenções adicionais. O objetivo desta série de casos é descrever quatro desfechos diferentes da técnica de coronectomia, em pacientes tratados por meio de um único protocolo. Os desfechos pós-operatórios apresentados variaram entre casos assintomáticos até migração das raízes, infecção e necessidade de remoção do remanescente radicular. Entretanto, apesar da variedade de desfechos, nenhum dos pacientes apresentou lesão ao nervo alveolar inferior. Desta forma, conclui-se que o objetivo principal da técnica foi alcançado apesar dos diferentes desfechos.

Termos de indexação: Nervo mandibular. Cirurgia bucal. Dente serotino.

$\boldsymbol{\nabla} \boldsymbol{\nabla} \nabla \boldsymbol{\nabla}$

1 Universidade Católica de Pelotas, Curso de Odontologia. Rua Gonçalves Chaves, 373, 96015-560, Pelotas, RS, Brasil. Correspondence to: LB MOURA. E-mail: <lucasbmoura@gmail.com>.

2 Universidade Federal de Pelotas, Faculdade de Odontologia. Pelotas, RS, Brasil.

$\checkmark \nabla v$

How to cite this article

Moura LB, Velasques BD, Barcellos BM, Damian MF, Xavier CB. Outcomes after mandibular third molar coronectomy. RGO, Rev Gaúch Odontol. 2020;68:e20200006. http://dx.doi.org/10.1590/1981-86372020000063688 


\section{INTRODUCTION}

Coronectomy, described by Ecuyer \& Debien in 1984 , is an effective alternative technique to mandibular third molar removal, when the dental roots are in close relationship with the mandibular canal. The technique goal is to avoid inferior alveolar nerve (IAN) impairment [1-3]. The intimate relationship between the dental roots of the lower third molars and the IAN can be identified on the panoramic radiograph, and some signs can be spotted: IAN shadow overlapping the roots of the lower third molar; narrowing of the canal and deviation of the canal [4]. Cone-Beam Computed Tomography (CBCT) is indicated to confirm the diagnosis since it allows the analysis of the real positioning of the dental roots to the mandibular canal, making possible to predict the possible risks of complications, such as paresthesia [5].

The possible complications of coronectomy include pain, edema, hemorrhage, infection, trismus and paresthesia, expected results after any surgical procedure of third molar removal. However, coronectomy presents particular postoperative outcomes, such as migration of the remaining roots which is quite frequent - occurring between $14-81 \%$ of the cases, with an average migration of 2 to $4 \mathrm{~mm}$. The migration can lead to exposure of the remaining fragments to the buccal mucosa, which will require a second intervention [1, 6-8].

The aim of this study is to present a series of clinical cases in which inferior third molars underwent a coronectomy surgical procedure, focusing the possible postoperative outcomes related to this technique.

\section{CASE REPORT}

This case series describes four different outcomes from lower third molar coronectomy. All patients had the dental roots in close relationship with IAN, confirmed by $\mathrm{CBCT}$. All procedures were performed under local anesthesia with the same surgical protocol9. The chosen anesthesia was the indirect IAN block using mepicavaine 3\% with epinephrine 1:100.000. A vestibular incision was performed and the flap reflected. The osteotomy was performed in the buccal side, and the dental crown was exposed and cut. The odontosection angulation was performed according to the position and degree of impaction of the tooth. The remaining fragment was worn down until $3 \mathrm{~mm}$ below the alveolar bone crest to allow bone healing. The standard wound care was performed. The postoperative oral medications were Amoxicillin 500mg ( $3 x$ daily, during seven days); Ibuprofen $600 \mathrm{mg}$ ( $3 x$ daily, during four days), and Dipyrone 500mg (4x daily, during three days). The followup evaluation was performed at 7th, 90th, 360th, and 720th postoperative days. None of the patients presented IAN impairment in the postoperative evaluations. Table 1 contain details of each procedure.

\section{Case \#1}

A 25-year-old female patient, healthy, presented the tooth \#38 (mesioangulated, Class II, position A) in close relation with IAN. The coronectomy procedure was performed without complications. The postoperative

Table 1. Detailed data from the reported cases.

\begin{tabular}{|c|c|c|c|c|}
\hline & Case \#1 & Case 2 & Case 3 & Case 4 \\
\hline Patient info. & 25y, F, Healthy & $24 y, F$, Smoker & $52 y, F$, Healthy & 27y, F, Healthy \\
\hline Tooth & \#38 & \#48 & \#48 & \#48 with prior pericoronitis \\
\hline $\begin{array}{l}\text { Classification (Pell \& Gregori, } \\
\text { Winter) }\end{array}$ & Class II - A, Mesioangulated & Class II - C Mesioangulated & Class II - C Horizontal & Class II - B Mesioangulated \\
\hline Outcome after coronectomy & $\begin{array}{l}2 \text { years: roots migrated } 3.4 \\
\text { mm without exposure to oral } \\
\text { cavity or symptomatology }\end{array}$ & $\begin{array}{l}30 \text { days: } \\
\text { Pain, edema, trismus, and } \\
\text { purulent drainage }\end{array}$ & $\begin{array}{l}6 \text { months: spontaneous pain } \\
\text { and incomplete healing. } \\
\text { Residual enamel in remaining } \\
\text { roots }\end{array}$ & $\begin{array}{l}6 \text { months: roots migrated } \\
3,4 \mathrm{~mm} \text { to the bone crest } \\
1 \text { year: intraoral bulging }\end{array}$ \\
\hline Additional treatment & None & Antibiotic treatment & Removal of residual enamel & Removal of retained roots \\
\hline $\begin{array}{l}\text { Outcome after additional } \\
\text { treatment }\end{array}$ & None & $\begin{array}{l}\text { In } 3 \text { years: roots migrated } \\
10.5 \mathrm{~mm} \text { without exposure } \\
\text { to oral cavity. }\end{array}$ & $\begin{array}{l}1 \text { year: roots migrated } \\
0,74 \mathrm{~mm}\end{array}$ & None \\
\hline
\end{tabular}


period was uneventful. In 2-years follow-up, the retained roots migrated $3.35 \mathrm{~mm}$ without exposure to oral cavity or symptomatology (figure 1ab).

\section{Case \#2}

A 24-year-old female patient, smoker, had the tooth \#48 (mesioangulated, Class II, position C) in intimate relation with IAN. The coronectomy procedure was performed without complications. However, in 30 days postoperatively, she showed pain, edema, trismus, and purulent drainage in the region. The acute treatment consisted in analgesics, antibiotics, local hygiene and mouthwash with $0.12 \%$ chlorhexidine, then the infection was solved without additional surgical procedure. In 3-years follow-up, the retained roots migrated $10.5 \mathrm{~mm}$. Despite the considerable migration, it is possible to verify adequate bone healing without exposure to oral cavity (figure $1 \mathrm{~cd}$ ).

\section{Case \#3}

A 52-year-old female patient, healthy, had the tooth \#48 horizontal in Class II, position C. The procure was performed without complications, however due to tooth position it was difficult to remove the dental crown. Six months postoperatively, the patient reported spontaneous pain. Clinically, incomplete healing of the mucosa was observed. The tooth \#47 presented positive response to vitality test, and the panoramic x-ray demonstrate residual enamel in the tooth \#48 remaining fragment. Therefore, an additional surgical procedure was performed to remove the residual enamel (figure 1ef). The postoperative period was uneventful, and an adequate healing occurred. In 1-years follow-up, there were no symptoms and radiological evaluation demonstrate successful bone healing, and 0.74 $\mathrm{mm}$ migration of the retained roots.

\section{Case \#4}

A 27-year-old female patient, healthy, showed acute pericoronitis in tooth \#48 (mesioangulated, Class II, position B). After treatment of pericoronitis, the tooth was submitted to coronectomy. Six-month follow-up the patient was asymptomatic, however, it was observed a considerable migration of the remaining fragment, $3.4 \mathrm{~mm}$ to the bone crest. At 1-year postoperative, she reported intraoral bulging in the region. Thus, the retained roots

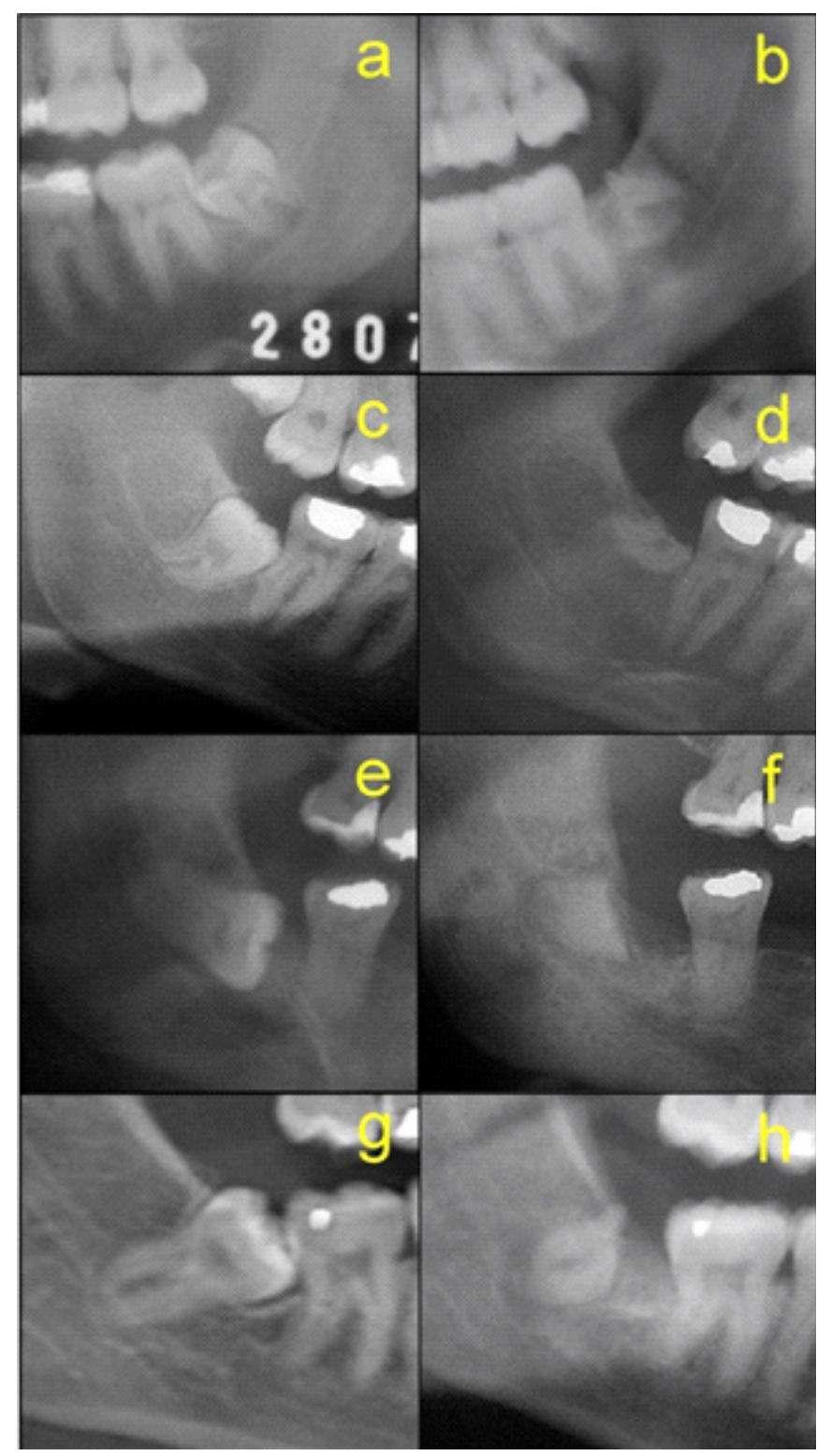

Figure 1. a. preoperative $x$-ray, case \#1. b. 2-years postoperative x-ray showing 3.4 $\mathrm{mm}$ migration. c. preoperative $x$-ray, case \#2. d. 2-years postoperative x-ray showing $10.5 \mathrm{~mm}$ migration and bone healing. e. preoperative x-ray case \#3. f. 1-year postoperative x-ray showing $0.74 \mathrm{~mm}$ migration. g. preoperative $x$-ray case \#4. h. 1-year postoperative x-ray showing $3.4 \mathrm{~mm}$ migration and exposure of the remaining roots.

were removed (figure 1gh). Histological analysis did not show presence of enamel, and the postoperative period was uneventful.

\section{DISCUSSION}

Impacted third molar removal is one of the most performed procedures in oral surgery. The coronectomy is 
an alternative technique that should be applied in specific cases where there is a high risk of IAN impairment $[6,9]$. The success of coronectomy depends on the survival of the retained roots and the bone healing around them [10]. The root wear during the surgical procedure aims to achieve root retention without migration [7]. However, significant root migration is a continuous physiological process and do not mean failure. The $10.5 \mathrm{~mm}$ migration found in case \#2 is higher than the average described in the literature $[5,11]$. However, it was harmless to the patient, since it was asymptomatic and did not require additional surgical procedure. We believe the initial inflammatory process may have exacerbated the roots migration, and after treatment the migration process stabilized.

According to Patel et al. [12], root migration will rarely result in exposure to the oral cavity. However, when it occurs, removal should be considered due to the risk of infection correlated to bacterial plaque accumulation. In Case \#4, the removal of the remaining roots was chosen because the patient reported discomfort caused by the eruption of the roots. To the best of our knowledge, the additional surgical procedure to remove exposed roots still can be considered success. Since the root migration makes the extraction of roots safer, and achieve the main objective of the coronectomy which is to not cause damage to the IAN. This aspect is also supported by Monaco et al. [7] that considers the root migration away from the mandibular canal result in an easier extraction.

Pogrel et al. [6] contraindicates coronectomy in cases where the tooth is in a horizontal position, because it may increase the difficult of the technique's execution. In the case \#3, an additional intervention was required to remove residual enamel, that did not allow adequate healing and bone formation. This finding is consistent with the literature, which describe residual enamel as an important factor associated with failure. The residual enamel acts as an obstacle to bone healing, therefore it was necessary the additional procedure $[6,8,9]$.

Although the maximum follow-up recommended in the literature is six months [9]. The reported cases were evaluated at 7, 90, 360 and 720 days. We believe that a larger follow-up is desired, since the root migration and exposure can occur in a late period, as observed in case \#4.

\section{CONCLUSION}

Considering the reported cases, it is possible to conclude that the coronectomy is an efficient and alternative technique to mandibular third molar removal, when the dental roots are in close relationship with the IAN. Particular outcomes are expected, especially root migration. However, in cases of residual enamel or exposure, an additional procedure will be necessary. In all cases, the IAN function was preserved, therefore the main goal of the technique was achieved.

\section{Collaborators}

MOURA LB and VELASQUEZ BD were the surgeons responsible to perform the procedures and the composition of the article; BARCELLOS BM performed the composition of the article, and postoperative evaluations; DAMIAN MF was responsible to perform the radiographic data evaluation; XAVIER CB was responsible for the critical revision and composition of the article, and supervised the surgical procedure.

\section{REFERENCES}

1. Renton T, Hankins M, Sproate C, McGurk M. A randomised controlled clinical trial to compare the incidence of injury to the inferior alveolar nerve as a result of coronectomy and removal of mandibular third molars. Br J Oral Maxillofac Surg. 2005;43(1):7-12. http://dx.doi.org/10.1016/j.bjoms.2004. 09.002 .

2. Leung YY \& Cheung LK. Safety of coronectomy versus excision of wisdom teeth: a randomized controlled trial. Oral Surg Oral Med Oral Pathol Oral Radiol Endod. 2009;108(6): 821-827. http://dx.doi.org/10.1016/j.tripleo.2009.07.004

3. Long H, Zhou Y, Liao L, Pyakurel U, Wang Y, Lai W. Coronectomy vs. total removal for third molar extraction: a systematic review. J Dent Res. 2012;91(7):659-665. http://dx. doi.org/ 10.1177/0022034512449346

4. Pogrel MA. Coronectomy: Partial Odontectomy or Intentional Root Retention. Oral Maxillofac Surg Clin North Am. 2015;27(3):373-382. http://dx.doi.org/10.1016/j.coms.2015. 04.003

5. Kohara K, Kurita K, Kuroiwa Y, Goto S, Umemura E. Usefulness of mandibular third molar coronectomy assessed through clinical evaluation over three years of follow-up. Int J Oral Maxillofac Surg. 2015;44(2):259-266. http://dx.doi. org/10.1016/j.ijom.2014.10.003

6. Pogrel MA, Lee JS, Muff DF. Coronectomy: A technique to protect the inferior alveolar nerve. J Oral Maxillofac Surg. 2004;62(12):1447-1452. http://dx.doi.org/10.1016/j.joms.2004. 08.003

7. Monaco G, de Santis G, Gatto MR, Corinaldesi G, Marchetti C. Coronectomy: a surgical option for impacted third molars in close proximity to the inferior alveolar nerve. J Am Dent Assoc. 2012;143(4):363-369. http://dx.doi.org/10.14219/jada. archive.2012.0178 
8. Frenkel B, Givol N, Shoshani Y. Coronectomy of the mandibular third molar: a retrospective study of 185 procedures and the decision to repeat the coronectomy in cases of failure. J Oral Maxillofac Surg. 2015;73(4):587-594. http://dx.doi. org/10.1016/j.joms.2014.10.011

9. Pogrel MA. Partial odontectomy. Oral Maxillofac Surg Clin North Am. 2007;19(1):85-91. http://dx.doi.org/10.1016/j.coms. 2006.11.006

10. Gady J \& Fletcher MC. Coronectomy: indications, outcomes, and description of technique. Atlas Oral Maxillofac Surg Clin North Am. 2013;21(2):221-226. http://dx.doi.org/10.1016/j. cxom.2013.05.008
11. Goto S, Kurita K, Kuroiwa Y, Hatano Y, Kohara K, Izumi $M$, et al. Clinical and dental computed tomographic evaluation 1 year after coronectomy. J Oral Maxillofac Surg. 2012; 70(5):1023-1029. http://dx.doi.org/10.1016/j. joms.2011.09.037

12. Patel V, Gleeson CF, Kwok J, Sproat C. Coronectomy practice. Paper 2: complications and long term management. Br J Oral Maxillofac Surg. 2013;51(4):347-352. http://dx.doi.org/10. 1016/j.bjoms.2012.06.008

Received on: 17/9/2018

Final version resubmitted on: 10/6/2019

Approved on: 12/12/2019 